\title{
RISK ANALYSIS AND BEHAVIOR OF ELECTRICITY PORTFOLIO AGGREGATOR
}

\author{
Eusébio, Eduardo ${ }^{1}$, Sousa, Jorge de ${ }^{1}$, Ventim Neves, Mário ${ }^{2}$ \\ ${ }^{1}$ Instituto Superiorior de Engenharia de Lisboa, Instituto Politécnico de Lisboa \\ Rua Conselheiro Emidio Navaro, 1, 1959-007 Lisboa, Portugal \\ eaeusbio@deea.isel.ipl.pt; jsousa@deea.isel.ipl.pt \\ ${ }^{2}$ Faculdade de Ciências e Tecnologia, Universidade Nova de Lisboa \\ 2829-516 Costa de Caparica, Portugal \\ ventim@uninova.pt
}

\begin{abstract}
The scope of this paper is to adapt the standard mean-variance model of Henry Markowitz theory, creating a simulation tool to find the optimal configuration of the portfolio aggregator, calculate its profitability and risk.

Currently, there is a deep discussion going on among the power system society about the structure and architecture of the future electric system. In this environment, policy makers and electric utilities find new approaches to access the electricity market; this configures new challenging positions in order to find innovative strategies and methodologies. Decentralized power generation is gaining relevance in liberalized markets, and small and medium size electricity consumers are also become producers ("prosumers"). In this scenario an electric aggregator is an entity that joins a group of electric clients, customers, producers, "prosumers" together as a single purchasing unit to negotiate the purchase and sale of electricity. The aggregator conducts research on electricity prices, contract terms and conditions in order to promote better energy prices for their clients and allows small and medium customers to benefit improved market prices.
\end{abstract}

Keywords: Aggregation, Risk analysis, Portfolio optimization, Load profiles.

\section{Introduction}

Electricity generation nowadays presents a greater number of challenges related to reliability, sustainability and security of supply. The use of renewable resources in power generation has been adopted in most OECD countries as an answer to the climate change problems originated by the burning of fossil fuels in the traditional thermal plants to supply the ongoing increase in electricity demand. Portugal has been considered a pioneer country in electricity production from renewable sources and, in $2010,52 \%$ of the electricity consumed came from renewable sources [1].

In terms of the economic model, the electricity industry has evolved from a vertically integrated state-owned monopoly company (not subjected to the normal rules of competition) to a liberalized market where generators and consumers have the opportunity to freely negotiate the purchase and sale of electricity. The liberalization of the electricity market in Portugal to allow entry of independent power producers with long term contracts and the creation of active wholesale and retail markets came in a later stage. 
The importance of reducing the level of consumption is very strong. Nowadays the actual economic situation affects all the participants in the sector [2], consumers, producers and "prosumers", many hypotheses to decrease the bill to pay for electricity are considered, such as different energy suppliers, control load programs, load forecasting, smart-grid, smart-metering and smart-box.

This new electrical concepts allows the medium, small consumers and producers to integrate the satisfaction of the power system because they adopted the new distributed generation paradigm, opposed to the traditional power system, composed by medium and large power plants [1]

The small passive consumer evolves to an active player, participating in the generation of electricity and the provision of network services. In this context, both aggregators and companies can bring their customers, consumers, producers, consumers and traders to market [3] [4].

In a future with the smart-grids and smart-metering, the development of a new challenge in electric system has occurred, how to integrate these new consumers/producers, known as "prosumers", in this contest a new partner arises in the aggregator company.

\subsection{Purpose of the paper}

The scope of this paper is to show how an aggregator company with a portfolio of customers, consumers, producers and "prosumers", can adequately manage its selection of customers in terms of risk and profitability, computing his values. To achieve this purpose presents an adaptation of the theory of investment portfolios introduced in 1952 by Harry Markowitz.

The module CAEM-PA- Commercial Agents in the Electricity Market - Portfolio Aggregator, was created especially to deal with this type of non-financial assets. CAEM-PA gives the values of profitability and portfolio risk for the current portfolio, minimum variance point of portfolio and the layout of the efficient frontier where the optimal portfolios are located. Finally, the simulator computes the best optimum directions, in case the aggregator intends to increase the number of assets, thus allowing him, under negotiation conditions with an hypothetical future customer, to elaborate an adequate price proposal for energy sell.

The module CAEM-PA, also allows to view the matrix of variance-covariance between the assets in the portfolio, and the electrical interpretations that can be done.

\subsection{Outline of the paper}

This paper is organized as follows; Section I, provides an introduction on power systems, expected developments and presents the new concepts of aggregators and "prosumers". The second section relates to the topic under study, "Technological Innovation for Cloud-based Engineering Systems". In Section III, following a literature study is made. Some techniques for portfolio evaluation are presented as well as a vision of the future in electrical distribution, regarding in particular the distributed energy resources. Section IV, Presents the methodologies applied to the study and characterizes the assets of the portfolio, consumers, producers and "prosumers", an explanation of the mathematical treatment used to obtain the behavior, risk and profitability, of the aggregator company is also included. Section 
$\mathrm{V}$, a case study of the portfolio aggregator is developed with the help of the CAEMPA module. Finally in section VI, the paper ends with some conclusions.

\section{Benefits from cloud-based engineering systems}

The new business relationship in the market presented in this study is based in a contractual relationship established between the aggregator and their customers.

Aggregator companies can use the cloud in their businesses as a way to help them expand their current commercial offerings without major investments.

Another important aspect is the effect of the cloud on small and medium size enterprises, the cloud allows them to have unrestricted access to certain geographic locations, which due to cost limitations would not have access, giving them an ability to act globally with a significant reduction in overhead cost.

The cloud also allows overcoming language barriers through centralized translation services and increases entrepreneurship, providing businesses and their collaborators the opportunity to exchange ideas, develop products quickly and economically.

\section{Background}

\subsection{Portfolio theory}

The Portfolio Theory has its origins in the scientific article Portfolio Selection of Nobel Economy Harry Markowitz, a result of his doctoral dissertation [5]. In this article, Markowitz addresses the choice of portfolios of financial assets with uncertain future value, following a criterion completely new at the time: the expected return criterion, variance of returns.

The return was considered to be the only important aspect on an investment without taking account their variability. But in fact, we observe in financial markets that investors consider different portfolios with a variety of assets portfolio without considering only the return that was suggested.

Markowitz intuited that different choices of investors and diversification were based on two notions distinct: the notion of trade-off between return and risk of investments and the notion of interaction between the returns of different assets.

Markowitz then suggests that the return of asset must have two reference measures: its expected value and its risk [6].

\subsection{Commercial agents, aggregators}

Networks of the future based on smart-grids concept evolution have great flexibility, and assume an involvement of the end users known by active demand [7] [8]. This new concept of dealing with energy level consumption, decreasing his level because the aggregator tries to optimize the load diagrams of its customers in order to create an aggregator global load diagram more smooth, more friendly to the systems operation. Charges like water heaters, electric radiators, heat pumps, battery EV's, can be controlled, via communication with "energy box" installed in the customers home.[9][10][11]. 
An aggregator provides its customers with energy marketing services, see Fig. 2, giving them access to market prices by adding a significant number of loads, at the same time grants the aggregator power negotiation in the electricity market [12] [13].

The aggregator makes an energy balance at the level of customers, who have contract with him, including forecasting consumption to meet energy produced and introduced into the distribution system, performing a service of high value to the system operator [14].

The action of the aggregator between his customers (consumers, producers and "prosumers"), and the grid operator, can reduce or adequate the consumption to the production in an active way, that contributes to decrease the dependence from imported electricity and increases the participation of the renewable energy in the local energy mix [14]. The cooperation between aggregator and customers promotes environmental benefits.

\section{Modeling methodology}

The customer portfolio module simulator, that includes several consumers, producers and "prosumers", with aggregator contract for energy supply and purchase, consists in three modules the CAEM-PA (portfolio evaluation), the EMT (energy negotiated) and the FLPP (energy and price forecast).

The CAEM-PA, main inputs are the historical data series of the customer, the contracted prices for sale and/or energy purchase predefined in the contract terms are indispensable; all this information is available (input) allowing, with appropriate treatment, obtain the output (risk, profitability, efficient frontier...), as depicted in Fig. 1.

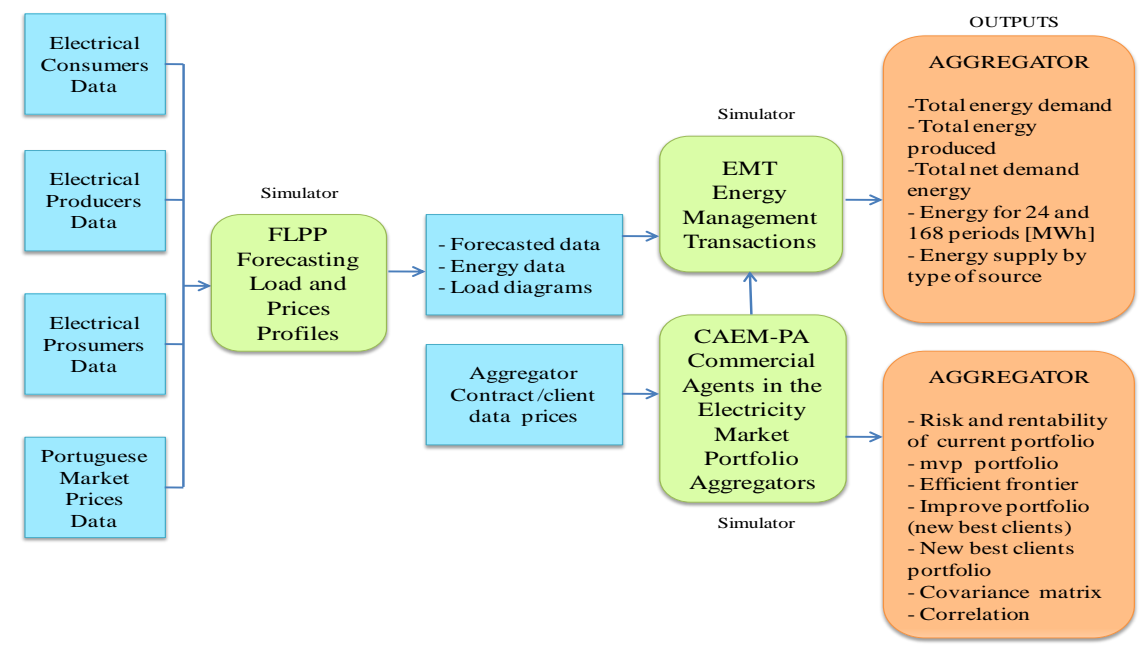

Fig.1. Simulator scheme, main inputs, intermediate data, outputs, for portfolio aggregator, risk and profitability estimation. 
In this paper the principal module of the complete scheme simulator is presented in Fig.2, with the inputs and outputs of the module CAEM-PA.

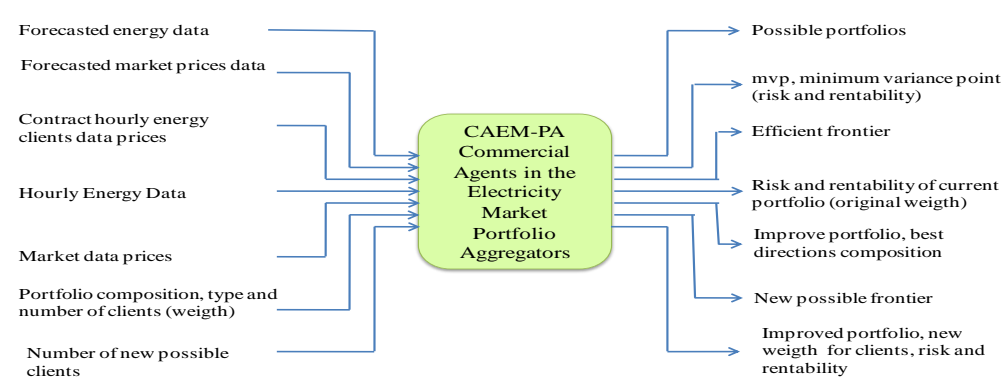

Fig.2. Commercial Agents Electricity Market - Portfolio Aggregator, inputs and outputs.

The profitability and risk of the portfolio for one entire week, 168 periods (hours), are computed, according to equation 1, and for its calculation a set of different scenarios of energy and prices are considered.

$$
E\left(R_{P}\right)=\sum_{i=1}^{n} E\left(R_{i}\right) \times w_{i}
$$

Where $E(R p)$ profitability of portfolio $P, E(R i)$ profitability of customer $i$, in the set of scenarios, and $w_{i}$ the weight of customer in portfolio $P, n$ is the number of customers in portfolio $P$, finally, $i$ is the type of customers in portfolio.

$$
\sigma_{P}=\sqrt{\sigma_{P}^{2}}
$$

Where $\sigma_{P}$ is the risk or volatility of the portfolio $P$.

$$
\sigma_{P}^{2}=\sum_{i=1}^{n} w_{i}^{2} \sigma_{i}^{2}+\sum_{i=1}^{n-1} \sum_{j=i+1}^{n} w_{i} w_{j} \sigma_{i, j}
$$

Where $\sigma_{P}^{2}$ is the variance of the portfolio $P, \sigma_{i}^{2}$ is the variance of client $i, w_{i}$ and $w_{j}$ are the weights of the customers in the portfolio and $\sigma_{i, j}$ the covariance between the customers $i$ and $j$, and $n$ the total number of different type of customers. The efficient frontier of the portfolio is obtained with equations 4 and 5 .

$$
\begin{array}{ll} 
& \min \quad \sigma_{P}^{2}=\sum_{i=1}^{n} w_{i}^{2} \sigma_{i}^{2}+\sum_{i=1}^{n-1} \sum_{j=i+1}^{n} w_{i} w_{j} \sigma_{i, j} \\
\text { s.a } & \sum_{i=1}^{n} E\left(R_{i}\right) w_{i} \geq E\left(R_{c}\right) \\
& \sum_{i=1}^{n} w_{i}=1 \\
& 0 \leq w_{i} \leq 1 \quad i=1,2,3, \ldots, n
\end{array}
$$




$$
\begin{array}{ll}
\max & E(R p)=\sum_{i=1}^{n} E\left(R_{i}\right) w_{i} \\
\text { s. } a \quad & \sum_{i=1}^{n} w_{i}^{2} \sigma_{i}^{2}+\sum_{i=1}^{n-1} \sum_{j=i+1}^{n} w_{i} w_{j} \sigma_{i, j} \leq \sigma_{v}^{2} \\
& \sum_{i=1}^{n} w_{i}=1 \\
& 0 \leq w_{i} \leq 1 \quad i=1,2,3, \ldots ., n
\end{array}
$$

\section{Case study}

The case study presented in this research is based on a set of customers as shown on Table 1. Different customer profiles, in one week time horizon, are considered, an example as depicted in Fig.3.
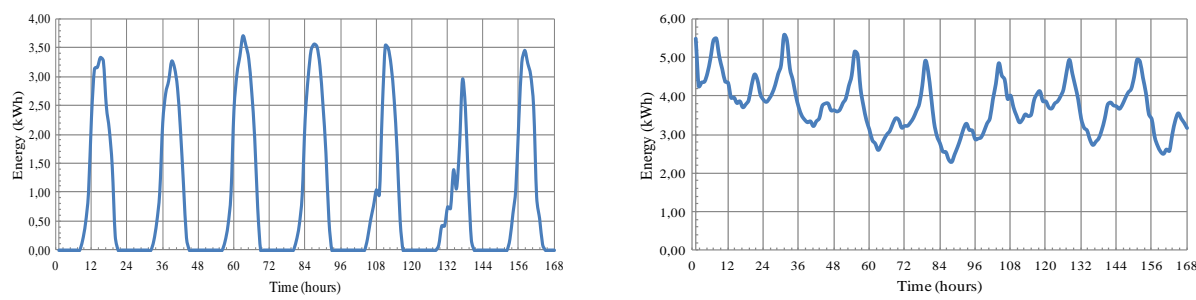

Fig.3. Load diagrams: a) Small photovoltaic producer and b) Small residential consumer.

Table 1. Type of customers portfolio and individual, weight, profitability and risk

\begin{tabular}{ccccc}
\hline & Type & Weight & Profitability & Risk \\
\hline Customer A & Consumer & 10 & 42,51 & 0,47 \\
Customer B & Consumer & 1 & 39,98 & 0,46 \\
Customer C & Consumer & 2 & 39,45 & 0,48 \\
Customer D & Consumer & 5 & 39,99 & 0,46 \\
Customer E & Consumer & 5 & 32,51 & 0,55 \\
Customer F & Consumer & 5 & 39,37 & 0,47 \\
Customer G & Consumer & 2 & 37,48 & 0,52 \\
Customer H & Consumer & 1 & 39,78 & 0,47 \\
Customer I & Producer & 1 & 13,55 & 0,66 \\
Customer J & Producer & 5 & 39,74 & 0,50 \\
Customer K & Prosumer & 10 & 1,00 & 1,10 \\
Customer L & Prosumer & 10 & 22,14 & 2,09 \\
Customer M & Prosumer & 5 & 27,37 & 0,76 \\
\hline
\end{tabular}


Fig. 4 shows the risk and profitability for the minimum variance point of the customer's portfolio, with risk and profitability value in the left side. The efficient frontier to the customer's portfolio is depicted on the right side.

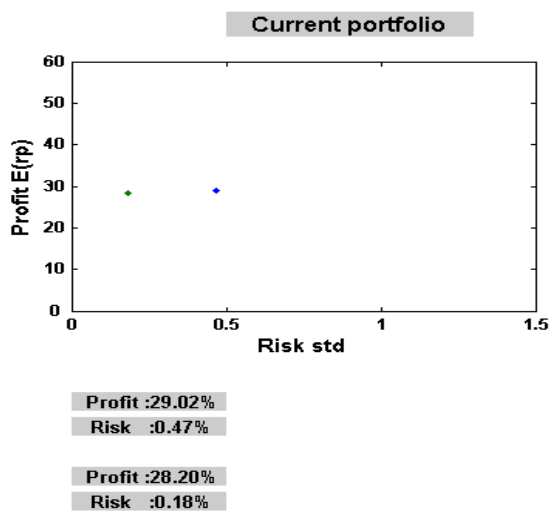

\section{Portfolio Set}

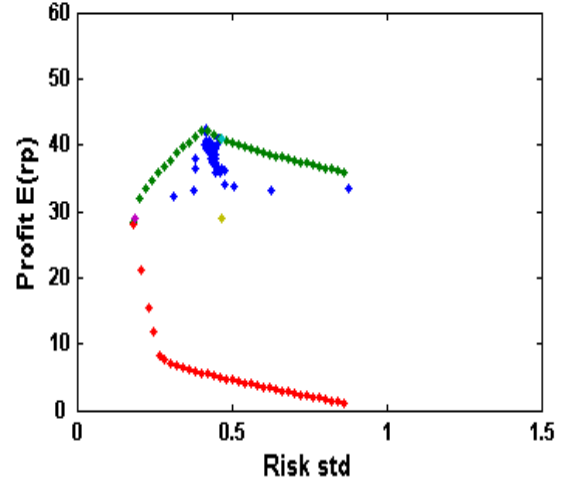

Fig. 4. Outputs of the module CAEM-PA, a) Minimum variance point with risk/ profitability, b) Efficient frontier of customer portfolio.

Fig. 5 shows the risk and profitability for optimum points of customers portfolio, as well as the possible evolution points of customers portfolio when new customers are included, depicted in the left side. A global vision with indication of the composition, weights of the assets, in percentage of the total for the new customer's portfolio composition, is depicted on the right side.
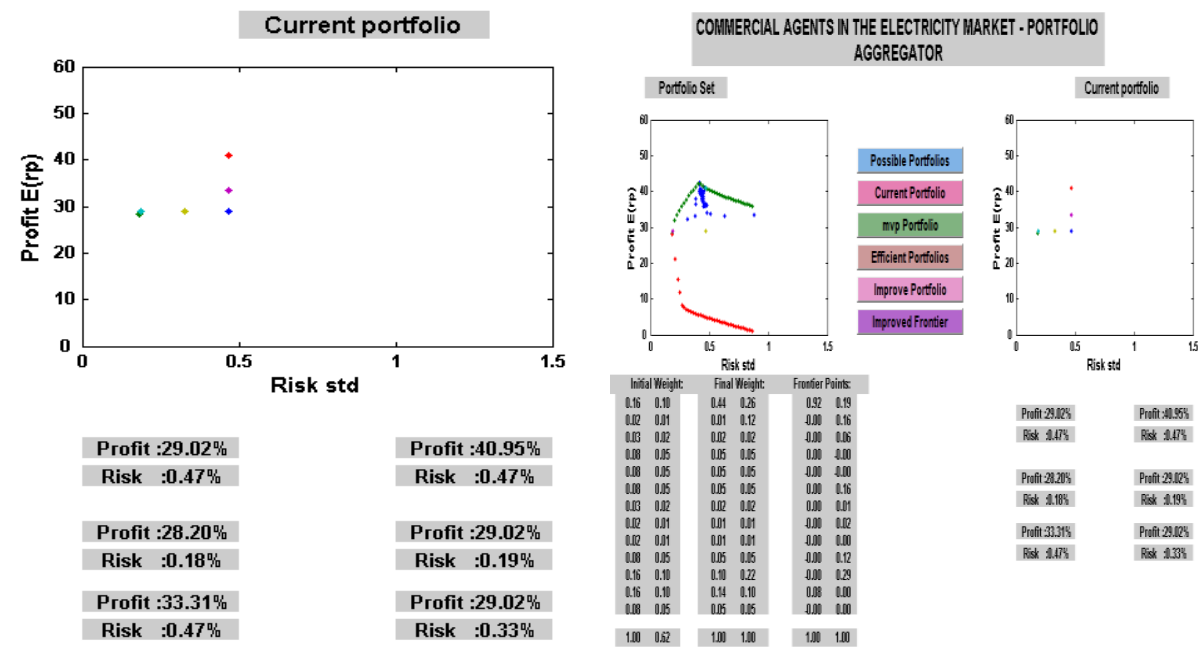

Fig. 5. a) Risk and profitability for the optimum points in de frontier and best points without discard any customer, b) Customers portfolio composition, and weights, for the referred best points. 


\section{Conclusions}

The module CAEM-PA, of the simulator, is able to deal and model an aggregator customer's portfolio; this tool computes profitability, risk, draws the efficient frontier, localization of the minimum variance point, position on the risk and profitability plan of customer's current portfolio. Besides, for all the significant points it is given the weight of the specific customer type on customer's portfolio composition.

The CAEM-PA, also discusses the increase of the customers number portfolio without any initial client. The aggregator achieves with this tool an important knowledge to create price proposals for negotiation process with potential new customers. In further works, the importance of the variance-covariance matrix is discussed, and the simulator allows to create an historical data with risk and profitability which is useful for VaR (value at risk) computation, as well as the energy quantities traded are developed by the Energy Management Transactions module.

\section{References}

1. Hossain, M., R,, Than Oo, A., M., Ali, A., B., M., S., "Evolution of Smart Grid and Some Pertinent Issues", Universities Power Engineering Conference, AUPEC, 2010.

2. UNRIC, http://www.unric.org/pt/actualidade/30866-relatorio-da-onu-a-crise-da-divida-dazona-euro-continua-a-ser-maior-ameaca-a-economia-mundial-e-preciso-inverter-politicasde-austeridade, (last time accessed 11/10/2013).

3. Lampopoulos, I., Vanalme, G. M.A., Kling, W. L., "A methodology for modeling the behavior of electricity prosumers within the smart grid", IEEE ISGT Europe 2010.

4. Stern, P. C., "Information, Incentives, and Proenvironmental Consumer Behavior," Journal of Consumer Policy, vol. 22, pp. 461-478, 1999.

5. Markovitz, H., Sharpe, W. F., Miller, M., "Founders of modern finance: their Portfolio Selection", Journal of Finance, volume VII, $\mathrm{n}^{\circ}$ 1, 1952.

6. Markovitz, H., "Portfolio Efficient: Efficient Diversification of Investments", Wiley \& Sons, New York, 1959.

7. Badano, A., "Regelverk Intelligenta Elnat och Smarta Matsystem", Energy Markets Inspectorate, EI R2011:03, 2011.

8. ADDRESS: http://www.adressfp7.org/, EC FP7 project ADRESS (ECGA no. 207643),last time accessed 10/10/2013.

9. Piette, M., A., et al, "Development and Evaluation of Fully Automated Demand Response in Large Facilities", Demand Response Research Center, January 2005.

10. Camus, C. Farias, T., Esteves, J., "Potential impacts assessment of Plug-in electric vehicles on the Portuguese energy market", Elsevier, Energy Policy Journal, volume 39, issue 10, pages 5883-5897, Ouctober 2011.

11. Hadley, S. W. \& Tsvetkova, A., "Potential Impacts of Plug-in Hybrid Electric Vehicles on Regional Power Generation". Oak Ridge National Laboratory, 2008, available http://www.ornl.gov/info/ornlreview/v41_1_08/regional_phev_analysis.pdf, (last time accessed 14/09/2012)

12. Eusébio, E., Sousa, J., Ventim Neves, M., "Commercial agent's portfolio optimization in electricity markets, European Electricity Markets - EEM12, April 2012.

13. Bollen, M., "Adapting Electricity Networks to a Sustainable Energy System", Energy Markets Inspectorate, EI R2011:03, 2011.

14. Lambert, Q., "Business Models for an Aggregator-Is an aggregator economically sustainable on Gotland?", MsC thesis, XR - EE - ICS 2012:003, Sthockholm, Sweden, 2012. 